\title{
Revista Feminina e a Cultura de Narciso: Anotações Sobre a Construção do Corpo ${ }^{1}$
}

\author{
Cabral, Amanda Rosas ${ }^{2}$ \\ Vandresen, Monique ${ }^{3}$
}

Resumo: Analisa o papel da revista feminina na composição de uma cultura narcisista, através da leitura de espaços, nestas publicações, que valorizem a magreza e a procura por cirurgias plásticas. Utiliza referencias teóricas da Psicologia, Comunicação e História. Conclui com uma discussão em torno da relação entre moda, beleza e tecnologia, analisando a influência destes conceitos sobre os ideais de beleza.

Palavras-Chave: Jornalismo. Feminino - Gênero. Informação.

\begin{abstract}
"Mas a moda não foi somente um palco de apreciação do espetáculo dos outros; desencadeou, ao mesmo tempo, um investimento de si, uma autoobservação estética sem nenhum precedente. A moda tem ligação com o prazer de ver, mas também com o prazer de ser visto, de exibir-se ao olhar do outro. Se a moda, evidentemente, não cria de alto a baixo o narcisismo, o reproduz de maneia notável, faz dele uma estrutura construtiva e permanente dos mundanos, encorajando-os a ocupar-se mais de sua representaçãoapresentação.” Lipovetisky (1989: p.39)
\end{abstract}

Este trabalho se propõe a analisar questões do narcisismo aplicadas à moda, analisando artigos, livros e revistas femininas. O tema foi escolhido por ser um assunto que está em voga na sociedade contemporânea, o qual tem uma repercussão até patológica. A procura por cirurgias plásticas e doenças como a anorexia e a bulimia são exemplos de como o sistema de moda e o narcisismo podem agir de uma forma negativa. As revistas femininas também geram um grande apelo - nem sempre diretamente - para tais práticas. Neste trabalho queremos mostrar uma parte marginal do mundo da moda, o qual é tão apreciado, importante e ativo na sociedade.

\footnotetext{
${ }^{1}$ Projeto de Pesquisa Revista Feminina: Um Mapa do Gênero Editorial. Centro de Artes da UDESC. Coordenação: Prof. Dra Monique Vandresen, Departamento de Moda.

${ }^{2}$ Bolsista PIVIC/MODA/UDESC. Também participam do projeto as bolsistas Carolina Fanti Negri (MODA/PIBIC) e Fernanda Brada Penteado (MODA/PIVIC).

${ }^{3}$ Orientadora
} 
O trabalho proposto analisa por intermédio da psicologia, literatura sobre beleza e moda como é formado o sentimento narciso, como a cultura capitalista assumiu uma postura de 'Cultura do Narcisismo', a maneira que as revistas de moda implantam a mesma e a maneira como esta cultura é recebida. Metodologicamente, o caminho começa a ser traçado a partir de uma leitura sobre beleza, de Umberto Eco, onde se percebe que em cada época existe um ideal de beleza, montado sob influências da massa, a qual é desejável que seja alcançada. O que se conclui também é que conforme a história foi passando, a tecnologia teve uma grande influência sobre os ideais de beleza, assim sendo cada vez mais complexo o caminho para alcançá-la. A leitura de textos acadêmicos de psicologia também foi importante para a pesquisa de como surge o sentimento narciso e como o mesmo é desencadeado nas pessoas. Autores como Lipovetsky (1989) nos fornecem uma base sobre o sistema de moda e o caráter efêmero do mesmo.

No desencadear da história, um dos processos que foi de notável aparição, foi o fato de que diante da perda de referências éticas e religiosas, descrença em ideais políticos e coletivos e da ausência de um compromisso social, as pessoas começaram a substituir seus ideais culturais por idéias particulares, que visavam o seu próprio prazer. A ideologia que passou a ser implantada era publicitária de prazer e consumo, a qual visava uma lógica do capital, e nesta as pessoas resgatam um narcisismo que fora nocauteado. Esta lógica, juntamente com a dos produtos, se tornaram um estilo de vida e a publicidade serviu para mobilizar os desejos do consumidor, prometendo uma estabilidade social.

As culturas capitalistas modernas assumiram a forma de 'Cultura do Narcisismo', principalmente nas últimas duas décadas, e assim uma enorme preocupação com a realização pessoal pode ser observada mais atentamente, e junto com este fato aconteceu um desinvestimento do mundo ao redor e de projetos coletivos. Neste mundo do 'próprio eu', os ideais de consumo assumem uma grande relevância e se tornam uma fonte de identidade e forma da máxima realização pessoal. Dentro deste aspecto, a beleza é cada vez mais reivindicada pela indústria cultural, e passa a ser um bem adquirido através do consumo.

Diante das perdas de referências citadas, as pessoas passam a ser regidas por sentimentos de desamparo e impotência. Uma angústia coletiva resulta deste fenômeno 
e, frente a uma realidade externa, acontece um desinvestimento da libido pessoal dos ideais e objetos e são acionados mecanismos de autodefesa; assim as pessoas se refugiam em seu próprio ego narciso.

Para Lasch (1987), como referido, a "cultura do narcisismo" é definida como uma cultura de "sobrevivência" de um "mínimo eu" que diante das previsões catastróficas anunciadas neste final do século $\mathrm{XX}$, ou seja, diante da iminência da guerra nuclear, do sentimento de impotência ante uma burocracia desumanizante e impessoal, da descrença nos ideais políticos-coletivos, do descrédito nas autoridades constituídas, como elemento estabilizador do caos social, do generalizado descompromisso social e ético e da decadência dos próprios vínculos afetivos significativos, os indivíduos passam a buscar soluções regressivas nas quais desaparecem as distinções entre ilusão e realidade, fortalecidas pelas "tecnologias do self" e pela ideologia publicitária do prazer e do consumo. A necessidade de ilusões diante de um mundo que perdeu suas "memórias coletivas" e suas "utopias" se intensifica cada vez mais, passando a volição individual a tornar-se todo-poderosa, aos moldes da onipotência narcísica.

Estamos aí diante da elevação do narcisismo, seja através do aumento do medo o que leva cada um a pensar somente em si. É observado que para a limitação do narcisismo são necessários veículos sociais numa coletividade, e estes se encontram dissolvido, na nossa cultura contemporânea em "tendências" e "desejos"; e estas são identificadas como ideais de consumo. Entretanto, diferente de veículos sociais que inibiam este sentimento narciso, os novos ideais promovem a ideologia de consumo, o narcisismo e a competitividade. A ideologia de consumo, apesar de trazer satisfação e prazer a seus membros, não aponta para nenhum projeto futuro, e assim ela faz uma maquiagem na verdadeira vontade de realização dos mesmos. Desta forma, as pessoas mergulham em falsas projeções, onde sempre estarão em busca dos seus desejos e de sua realização pessoal, a qual dificilmente será alcançada. A busca por este sentimento perdido é sempre reforçada quando a mídia mostra novos ídolos, objetos e modelos ideais a serem incorporados ou copiados.

O processo de idealização se faz quando o indivíduo desconhece a falta e vê na aquisição de alguns bens a sua completude. Este consumidor faz um universo imaginário ao redor de uma mercadoria. Dentro de infinitos produtos que o indivíduo procura para a sua realização pessoal, alguns são os que mexem em seu próprio ser, entre eles estão roupas, cosméticos e cirurgias plásticas, os quais servem para encobrir a 
"fragilidade dos nossos corpos". O corpo sempre foi constituído em diferentes formas da utilização de recursos considerados certos para a construção da beleza, dentre eles mecanismos artificiais e sacrificantes. Nesta constituição, a moda sempre está ligada com a construção do corpo que sempre foi definido de acordo com a estética de cada época, porém, hoje o corpo é construído e destruído afetando o corpo natural.

O corpo é um gerador de linguagens. Dentro da moda, os trajes, adornos e etc., sobrepõe-se ao corpo como suporte da moda no qual esta constrói e consolida nossos desejos. As revistas femininas acabam usando destas estratégias em seus editoriais e em suas propagandas. O que acontece é uma busca desenfreada pelo que a mídia impõe, e desta maneira, as pessoas buscam desde simples soluções até formas de mutilação corporal para alcançar o que é dito como certo. Estas são sempre usadas pela indústria cultural e pela publicidade como forma de mitigar o sentimento de impotência, seja da decrepitude do corpo ou do fracasso para atingir os ideais pessoais.

A moda torna-se cúmplice dessas mutilações utilizando uma de suas maiores seduções - a mutabilidade. A construção da aparência envolve conceitos e práticas culturais corporificadas através de armações, estruturas e materiais. Ao utilizar modelados corpos que refletem o gosto da sociedade atual, usando roupas ajustadas, transparências, recortes e exposição de seios siliconados, o sistema de moda consegue chamar atenção para tais praticas. Os meios de comunicação em geral dão uma grande ênfase a estas práticas, dando uma espécie de certificado para quem as segue, valorizando esta atitude com a massificação do uso da imagem das mesmas. Outra característica que vale ressaltar é que na sociedade contemporânea os mecanismos artificiais de criações das formas se tornaram obsoletos, assim, uma maior ênfase foi dada ao corpo; agora se constrói o próprio corpo.

Com impulsos dados pela cultura, algumas ações responsáveis por incidirem diretamente no corpo e acabam por dotá-lo de novos significados. A pessoa por meio do corpo revela uma necessidade extrema de querer significar, e ele é, antes de tudo, um corpo imaginário, esse que busca práticas estéticas que chamem a atenção para si.

O corpo na contemporaneidade é visto como mercadoria, objeto de consumo e alvo de investimentos. A cultura do corpo obcecada por ideais de perfeição, concentra nele investimentos financeiros, simbólicos, afetivos e assim desvia esse fundo de outros investimentos. Essa concentração implica em alienação, e assim unifica todos os corpos em um único padrão. Muitas vezes o desejo de ter um novo corpo é maior do que de ter determinada roupa ou carro. O corpo, o presentifica em todo o lugar e é um campo de 
controle simbólico e com a cultura das aparências, ele se sobrepõe a questões ligadas a saúde e os riscos são colocados em segundo plano.

“(...) O superastro da nova moda é o corpo, e este se tornou o loca do consumo conspícuo. Talvez não sejamos capazes de distinguir o rico do pobre com suas roupas pretas, relógios bolsas, mas as chances são maiores do rico ser bem mais magro. É provável que o rico tenha o corpo esculpido com exercícios na academia, orientação de um personal trainer, lipoaspiração e, possivelmente implantes, o corpo do rico será muito mais caro de ser mantido e demonstrará isso.” Etcoff (1999:259)

O produto acaba servindo como espelho, não apenas da imagem real, mas da fantasia idealizada.

No Brasil, percebemos que a população se encaixa com todas as idéias levantadas neste artigo, o país é campeão em número de intervenções estéticas e só em 2005, foram realizadas 650 mil intervenções em clínicas brasileiras (15\% entre jovens de 14 e 18 anos; $82 \%$ são mulheres).

Concluímos neste artigo, com base em referenciais teóricos e pesquisa em revistas femininas, que as revistas e os editoriais encontrados sobre beleza e estética nas mesmas tendem a sugerir soluções drásticas para a auto-estima e estética das mulheres. Ao contrário do que seria o correto para a saúde, as cirurgias e intervenções estéticas são mostradas como simples, rápidas e eficazes, anteriormente até de sugestões de tratamentos com nutricionistas e outros alternativos. As matérias nas revistas são, em sua maioria, tendenciosas e mostram um padrão de beleza sugestivo para todos os tipos de mulheres seguirem. Não pretendo com este artigo afirmar o que é certo, porém, fazer uma crítica sobre a massificação do ideal de beleza e intervenções estéticas, já que nos últimos anos, o aumento das mesmas foi significativo, juntamente com casos de doenças como a anorexia ou a bulimia. Pretende-se assim, tentar contribuir para que exista uma consciência maior para distinguir o que devemos fazer com nossos corpos, e para que exista uma maior democratização dentro das revistas, as quais são de uma notável influência na escolha das mulheres brasileiras.

\section{Referências}

ECO, Umberto (Org.). História da beleza. Rio de Janeiro: Record, 2004.

CASTILHO, Kathia, GALVÃO, Diana. A moda do corpo e o corpo da moda. São Paulo: Esfera, 2002. 
QUEIROZ, Renato da Silva (Org.). O corpo do brasileiro: Estudos de estética e beleza. São Paulo: Senac, 2004.

GUMBRECHT, Hans Ulrich. Elogio da beleza atlética. São Paulo: Companhia das Letras, 2007.

NAVARRO, Andreya. Marketing da perversão: A nova economia do desejo. Rio de Janeiro: Universidade Candido Mendes, 2006.

MERLEAU - PONTY, Maurice. Fenomenologia da percepção. São Paulo: Martins Fontes, 1996.

SEVERIANO, Maria de Fátima Vieira. Sociedade de consumo e psicopatologias contemporâneas: uma reflexão sobre a formação de ideais numa cultura narcísica. Disponível em:

< http://www.fundamentalpsychopathology.org/anais2006/5.56.1.htm> Acesso em: 20 dezembro 2007.

ORTEGA, Francisco.Utopias corporais substituindo utopias sociais: Identidades somáticas e marcas corporais na cultura contemporânea. Rio de Janeiro.

ARAÚJO, Maria Lúcia. A mulher e o corpo ideal na contemporaneidade: uma questão entre o desejo e o gozo. São Paulo: 2001. Disponível em:

<http://www.ip.usp.br/laboratorios/lvida/coloquios/amulher.htm>

ETCOFF, Nancy. A lei do mais belo. Trad. Ana Luíza Borges de Barros. Rio de Janeiro: Editora Objetiva Ltda, 1999.

LIPOVETSKY, Gilles. O império do efêmero: a moda e o seu destino na sociedades Modernas. São Paulo : Companhia das letras, 1989. 